\title{
What do under 15 year old schoolboy rugby union players think about protective headgear?
}

\author{
C F Finch, A S McIntosh, P McCrory
}

\begin{abstract}
Objectives-When protective headgear is designed, the attitudes of the intended users needs to be taken into account, as well as safety performance criteria. The aim of this study was therefore to determine the attitudes of schoolboy rugby union players towards protective head-
\end{abstract} gear.

Methods-A survey of 140 rugby union players (82.4\% response rate) from 10 randomly selected school teams in metropolitan Sydney was conducted at the end of the 1999 playing season. All players were aged 14-16 years. All teams had participated in a trial of headgear during the 1999 season in which six of the teams had been assigned to a headgear trial arm and four teams to a control arm. Players completed a self report questionnaire during a supervised session at school. The questionnaire collected information on recent head injuries, use of protective equipment, and attitudes towards headgear.

Results-Some form of protective equipment was always worn by $76.1 \%$ of players: 93.6\% reported using a mouthguard and $79.3 \%$ a helmet/headgear during the 1999 season. The two most important reasons for wearing headgear were related to safety concerns. Players with no recent head/neck injury were more likely to report that they felt safer when wearing headgear $(p<0.001)$ and less likely to cite a previous injury as a motivating factor for wearing headgear $(p<0.001)$ than those who had sustained a recent head/neck injury. Of the players who wore headgear during the 1999 season, $67 \%$ said that they played more confidently when they wore headgear, but $63 \%$ said that their head was hotter. Few players reported that their head was uncomfortable $(15 \%)$ or that it was hard to communicate $(3 \%)$ when they wore headgear. The main reasons for not wearing headgear were related to its design features: uncomfortable $(61 \%)$ and it was hot $(57 \%)$.

Conclusions-The primary reason cited by players for wearing headgear is safety. Receiving an injury would also motivate non-wearers to wear headgear. Players report that they are more confident and able to tackle harder if they wear headgear, suggesting that a belief in its protective capabilities may influence behaviour. These attitudes need to be addressed in the design of effective headgear as well as in strategies to promote its use.

(Br f Sports Med 2001;35:89-94)
Keywords: headgear; rugby union; schoolboy; prevention; protection; safety

Rugby union football is an international game played in many countries on all continents. It is a contact sport involving two teams of 15 players in which the ball is carried, thrown, passed by hand, and kicked. Body contact occurs in many phases of play including when tackling an opponent with the ball and contesting the ball in scrums, lineouts, rucks, and mauls. Although intentional head contact is illegal-for example, tackling above shoulder height-it can occur in many phases of play. For example, a tackled player's head can strike the ground or the tackler's head can come into contact with an opponent's chest/shoulder.

Most studies of rugby injuries report that head and facial injuries account for $14-27 \%$ of all injuries. ${ }^{1-9}$ Of these, $60-80 \%$ are lacerations to the face or scalp and $5-10 \%$ are concussion.

Concussion in rugby can be reduced through enforcement of rules, attention to technique, team skills, and the use of personal protective equipment, in this case protective headgear. ${ }^{10}$ Protective headgear can also prevent lacerations to the face or scalp. Unlike American football, rugby headgear is soft and does not have a face guard.

Recent studies of protective headgear designed for use in rugby union, rugby league, and Australian football have found that the ability of current headgear to reduce concussion is minimal. ${ }^{11-13}$ There are, however, contrasting opinions about the desired or intended function of headgear particularly with regard to its role in abrasion/laceration protection versus protection against traumatic brain injury - that is, closed head injury. ${ }^{14}$ In rugby union, specific laws limit the nature and type of helmets that may be worn in matches. ${ }^{15}$ They restrict headgear thickness to $10 \mathrm{~mm}$, foam density to $45 \mathrm{~kg} / \mathrm{m}^{3}$, and headform acceleration in a drop test from $0.3 \mathrm{~m}$ to $200-550 \mathrm{~g}^{16}$

It has been suggested, although not formally shown, that rugby players wearing protective equipment become more aggressive or less cautious during play, thereby negating any benefit that may have been gained. ${ }^{17}$ In other words, the attitudes and behaviours of players towards protective headgear are important in the design and evaluation of its protective function. That attitudes towards protective equipment influence its use has been shown in a number of other activities such as cycling ${ }^{18}$ and squash. ${ }^{19}$

Adolescence is often a period of risk taking, which can be quite evident in sports participation. ${ }^{20}$ This risk taking behaviour is an important aspect of psychosocial development 
which can impact significantly on injury rates. ${ }^{21}$ If these heightened risk taking behaviours influence behaviours on the sporting field, and they are not accompanied by protective behaviours, they could lead to an increased risk of injury in adolescent players. In contrast, the level of adopted behaviours (such as use of protective equipment) declines in adolescents despite a greater understanding of risk situations than in younger children. ${ }^{22}$ This is particularly so for use of protective equipment to prevent sports injuries. ${ }^{18}$

This paper describes the attitudes of 14 and 15 year old male rugby union players about protective headgear. The cohort reported on are a subsample of 10 teams from a set of 16 that participated in a prospective study of football headgear in under $15 \mathrm{~s}$ rugby union in 1999. ${ }^{12}$ Although no survey of headgear wearing rates in these players has previously been reported, the rate of non-mandated or voluntary use in these junior age groups appears to be high, with some schools advocating headgear use and some teams having almost $100 \%$ wearing rates.

\section{Methods}

This study builds on a trial of headgear in schoolboy football teams involved in the $15 \mathrm{~A}$ - that is, under 15 years, A grade or highest standard of play - interschool football competitions conducted in $1999 .{ }^{12}$ All Sydney metropolitan based schools involved in two 15A interschool rugby union competitions were invited to participate in the earlier trial. Of the 22 schools approached, 16 agreed to participate in a trial of the effectiveness of protective headgear during the 1999 rugby union playing season. The results of this trial, involving teams allocated to either control or interventionthat is, headgear-arms, are reported elsewhere. ${ }^{12}$

A random sample of 10 of the 16 school teams participating in the headgear trial was selected and approached to participate in a survey of player attitudes towards protective headgear at the end of the 1999 rugby union playing season. It was not possible to survey all 16 teams because of logistic and financial constraints. Each of the 10 randomly selected school teams agreed to participate in this survey, giving a $100 \%$ team response rate. Of these, six wore headgear and four were controls in the earlier study.

All players from each of the 10 15A teams were invited to complete a self report survey about their attitudes towards protective headgear and their head injury history. Each team had 17 players ( 15 players +2 reserves), giving a potential total of 170 survey respondents. The surveys were conducted at the schools over a two week period at the completion of the 1999 playing season. The surveys were completed during a supervised session, largely to prevent participants from talking to each other and contaminating their responses. Not all team members were present at the time of the survey. In total, 140 players completed the survey giving an $82.4 \%$ player response rate.
Informed written consent was obtained from the parents of the players for their participation in this study according to a protocol approved by the ethics committee at the University of New South Wales.

A survey questionnaire containing 26 questions was developed to seek the players' attitudes towards protective headgear. The questionnaire was based on previous surveys of attitudes towards protective equipment conducted by one of the authors. ${ }^{18}{ }^{19}$ It included mainly closed option questions for ease of completion but some open ended options allowed provision of further detail. The questionnaire was pilot tested on a small group of rugby players who were asked to comment on the phrasing of the questions before the final format was finalised.

The survey form included questions designed to collect the following information:

- personal information (date of birth, school attended, year at school, suburb, and postcode of residence);

- participation history (years played rugby union; number of practice matches/ preseason competition matches played; number of weekly training sessions; usual position on the field);

- use of protective equipment and headgear (frequency of use of protective equipment; type of protective equipment used and the context of play in which it was worn; use of headgear during the preceding football season);

- attitudes towards headgear for those players who wore protective headgear for most of the 1999 playing season (reasons for deciding to wear the headgear; risk perceptions while wearing headgear; opinions about the headgear; good headgear design features);

- attitudes towards headgear of players who did not wear protective headgear for most of the 1999 playing season (reasons for deciding not to wear headgear; factors that would encourage them to wear headgear);

- history of head and neck injuries during the past two playing seasons (self reported number of head/neck injuries).

Most attitudinal and knowledge data were recorded in a five point Likert scale (always, often, sometimes, rarely, never). Questions asking about reasons for wearing/not wearing headgear and about good headgear design/ features gave a list of options from which the player was to choose the most appropriate answers. The wording of these attitudinal/ opinion questions and options is given in the tables.

After being coded, the data were double entered into an Excel spreadsheet and cleaned before being transferred to SPSS 8.0 for analysis. The proportion of players giving each response to the categorical variables was calculated with the associated 95\% confidence intervals. Data on the playing history were very skewed, and so medians and ranges are presented. For the Likert scale variables, the proportion of all responding players giving an "always" or "often" response was calculated. 
Table 1 Self reported use of protective equipment during rugby union

\begin{tabular}{lllll}
\hline \multicolumn{5}{l}{ Type of protective equipment } \\
\cline { 2 - 5 } Context of play & $\begin{array}{l}\text { Mouthguard } \\
(n=131)\end{array}$ & $\begin{array}{l}\text { Shoulder pads } \\
(n=51)\end{array}$ & $\begin{array}{l}\text { Ankle taping } \\
(n=14)\end{array}$ & $\begin{array}{l}\text { Helmet/headgear } \\
(n=111)\end{array}$ \\
\hline Training only & 0.8 & 0 & 14.3 & 0 \\
Games only & 36.6 & 84.3 & 64.3 & 54.1 \\
Both & 62.6 & 15.7 & 21.4 & 45.9 \\
\hline
\end{tabular}

Values are the proportion (\%) of all players who stated they used the particular item.

The attitudinal data are presented for the whole sample and separately for players involved in the headgear and control arms of the original headgear trial. For these analyses, players were classified on an "intention to treat" basis so they were assigned to control or headgear groups according to the initial randomisation of their team to these arms in the earlier trial and not on the basis of their actual behaviours. The attitudinal responses in these two groups were compared by $\chi^{2}$ tests.

Attitudinal responses were also compared in players with/without a self reported recent history of head/neck injury. This history was ascertained from the instruction: "specify how many head or neck injuries that you have suffered within the last 2 football seasons are as a result of your participation in football." Players whose response was at least one such injury were considered to have a recent head/neck injury history.

\section{Results}

DEMOGRAPHIC PROFILE

All of the surveyed rugby players were attending a secondary school. Of the 139 schoolboy rugby players who provided information about their year level at school, $59.0 \%$ were in year 9 and $41.0 \%$ in year 10 . All players were aged 14-16 years at the time of the survey and all were male. Over half $(60 \%)$ of the respondents were from teams who wore headgear in the earlier trial.

PLAYING HABITS AND INJURY HISTORY

Some $79 \%$ of the sample reported having played rugby union for at most eight years, with the median being six years (range 1-12). The median number of practice/preseason competition matches played during 1999 was eight games (range $0-52$ ), with $85.6 \%$ of survey respondents having participated in two to three training sessions a week. Just over half of the sample $(51.0 \%)$ played as forwards, $43.2 \%$ as backs, and $5.8 \%$ played in both forward and back positions.

Just under half of the sample $(44.3 \%)$ reported sustaining a head/neck injury during training/game play within the last two football seasons. These injured players reported between one and 10 head/neck injuries in the previous two playing seasons, with more than half $(59.9 \%)$ reporting just one such injury.

USE OF PROTECTIVE EQUIPMENT AND HEADGEAR When playing rugby union football, $76.1 \%$ of players reported always wearing some form of protective equipment, compared with $2.2 \%$ who never wore it. Table 1 describes the players' self report use of a range of protective equipment items, including mouthguards, shoulder pads, ankle taping, and helmet/ headgear. Most players reported using a mouthguard (93.6\% of all respondents) or a helmet/headgear $(79.3 \%)$. Fewer than $40 \%$ of the players reported wearing shoulder pads in any context of play, and only $10 \%$ reported using ankle taping. Very few players tended to wear protective equipment only during training sessions. Shoulder pads and ankle taping were more often used in the game only situation than in both games and training.

Overall, a high proportion of the sample $(79.3 \%)$ reported wearing protective headgear for most of the 1999 season. Not surprisingly, more players from teams allocated to the headgear trial arm wore protective headgear during the 1999 season than players from control teams $\left(89.3 \%\right.$ v $64.3 \%$ respectively; $\chi_{1}^{2}=$ 12.787, $\mathrm{p}<0.001)$.

REASONS FOR WEARING HEADGEAR

The 110 schoolboy rugby players who reported wearing headgear during the 1999 season were asked: "What were the two most important reasons for deciding to wear headgear?" Table 2 lists the most commonly cited reasons selected from a list of specified options. Overall, the two most commonly given reasons were related to safety/injury prevention. Players with no recent head/neck injury history were significantly more likely to say that they felt safer when wearing headgear, than players who had sustained a head/neck injury during the past two seasons $\left(\chi_{1}^{2}=7.73\right.$, $\mathrm{p}<0.001)$. Not surprisingly, players who had been injured during the past two years were more likely than the uninjured group to cite a previous injury as a major motivating factor

Table 2 Most important reasons cited for wearing protective headgear during the 1999 playing season

\begin{tabular}{llllll}
\hline & \multicolumn{2}{c}{$\%$ of players who wore headgear for most of the 1999 playing season } \\
\cline { 2 - 6 } Reason indicated & $\begin{array}{l}\text { All players } \\
(n=110)\end{array}$ & $\begin{array}{l}\text { Players with no recent } \\
\text { head/neck injury } \\
\text { history }(n=50)\end{array}$ & $\begin{array}{l}\text { Players with a recent } \\
\text { head/neck injury } \\
\text { history }(n=59)\end{array}$ & $\begin{array}{l}\text { Control team } \\
\text { players }(n=36)\end{array}$ & $\begin{array}{l}\text { Headgear team } \\
\text { players }(n=73)\end{array}$ \\
\hline I feel safer when I wear one & 54.1 & $\mathbf{6 2 . 7}$ & $\mathbf{3 6 . 0}$ & 52.8 & 49.3 \\
I don't want to get an injury & 42.2 & 44.1 & 40.0 & 50.0 & 38.4 \\
I like to & 20.0 & 23.7 & 10.0 & 11.1 & 20.5 \\
Participant in a study & 18.3 & 13.6 & 24.0 & 2.8 & $\mathbf{2 6 . 0}$ \\
I have had a previous injury & 14.7 & 5.1 & $\mathbf{2 6 . 0}$ & 10.0 & 11.0 \\
My parents make me & 9.2 & 8.5 & 6.0 & 0 & 6.8 \\
Everyone on my team does & 3.7 & 1.7 & 2.0 & 0 & 5.5 \\
My school makes me & 2.8 & 3.4 & & 4.1
\end{tabular}

Percentages within each column do not add to $100 \%$, because two reasons were given. Data relate to cases without a missing response. Bold pairs of values are significantly different. 
Table 3 Attitudes and beliefs about protective headgear and injury risk among players who wore protective headgear

\begin{tabular}{|c|c|c|c|c|c|}
\hline \multirow[b]{2}{*}{ Attitude/belief } & \multicolumn{5}{|c|}{$\%$ of all players who wore headgear for the majority of the 1999 playing season } \\
\hline & $\begin{array}{l}\text { All players } \\
(n=110)\end{array}$ & $\begin{array}{l}\text { Control team } \\
\text { players }(n=36)\end{array}$ & $\begin{array}{l}\text { Headgear team } \\
\text { players }(n=74)\end{array}$ & $\begin{array}{l}\text { Players with no recent } \\
\text { injury history }(n=60)\end{array}$ & $\begin{array}{l}\text { Players with a recent } \\
\text { injury history }(n=50)\end{array}$ \\
\hline Do you feel safer wearing headgear? & 83.6 & 88.9 & 81.1 & 83.3 & 84.0 \\
\hline Do you play more confidently if you are wearing headgear? & 67.3 & 80.6 & 60.8 & 66.7 & 68.0 \\
\hline Did your head feel hotter while wearing headgear? & 62.8 & 55.3 & 66.2 & 56.7 & 70.0 \\
\hline Do you think wearing headgear can prevent head injury? & 54.6 & 63.9 & 49.8 & 53.3 & 56.0 \\
\hline Do you feel that you could tackle harder while wearing headgear? & 54.6 & 63.9 & 50.0 & 55.0 & 54.0 \\
\hline Did your head feel uncomfortable while wearing headgear? & 14.7 & 8.6 & 17.8 & 13.6 & 16.0 \\
\hline Did you experience any communication difficulties while wearing headgear? & 2.7 & 5.8 & 1.4 & 1.7 & 4.0 \\
\hline
\end{tabular}

Values are the proportion of cases giving an "always" or "often" response to each attitude/belief.

for headgear use $\left(\chi_{1}^{2}=9.45, \mathrm{p}<0.001\right)$. Players who were members of the headgear teams during the formal trial were almost 10 times as likely to indicate that they wore headgear because they were part of a study than control team members $\left(\chi_{1}^{2}=8.70, \mathrm{p}<0.001\right)$. No other comparison of motivating reasons was significantly different in players from control and headgear teams.

ATTITUDES TOWARDS HEADGEAR

To determine the attitudes and beliefs of the surveyed players about headgear and injury, a series of questions were asked of players who reported wearing protective headgear $(\mathrm{n}=$ 110) while playing football. Table 3 gives their responses. Over $80 \%$ of all players felt safer when they wore headgear and a significant proportion played more confidently when they wore it. Although a large number of players felt that their head was hotter when they wore headgear during football, very few stated that their head was uncomfortable or that they experienced communication problems. There were no significant differences in the reporting of these attitudes between control and headgear players nor between those with and without a recent history of head injury.

The players who wore protective headgear for most of the 1999 playing season were also asked to indicate which features would make them select a brand or model of headgear. Players ticked up to seven of the given options provided. The main design features selected were "its looks/appearance" $(59.6 \%$ of respondents), "the size of it" $(49.5 \%)$, "information about its safety performance" $(45.0 \%)$, and "how heavy it feels" (43.1\%). Less often selected options were "how much it costs" $(38.5 \%)$, "its colour" (30.3\%), and "if a national or state representative player wore it" $(20.2 \%)$.

\section{ATTITUDES IN PLAYERS WHO DID NOT WEAR}

HEADGEAR

Only 28 players indicated that they did not wear headgear for most of the 1999 playing season. Of these, $64.3 \%$ did not have a recent history of head/neck injury, and $67.9 \%$ were members of control teams. These players were asked to indicate the two most important reasons they had for not wearing protective headgear from a list of seven specified options. The most commonly cited reasons related to the features of the headgear itself: "it is too uncomfortable" $(60.7 \%)$; "it is too hot" $(57.1 \%)$. Other commonly selected reasons were "I don't like to" (39.3\%) and "I don't need to" (25.0\%). Interestingly, only $7.1 \%$ of the players who did not wear headgear selected each of the options "they don't work" and "only wimps wear them".

For these players to wear headgear regularly, factors such as "having an injury" (86.2\% of cases) and "being made to by parents" ( $41.4 \%$ of cases) were the most important reasons provided by the players.

\section{Discussion}

The actual usage rates of protective equipment by schoolboy rugby union players in the general sporting community are unknown. After a randomised controlled study of rugby headgear in $1999,{ }^{12}$ a subgroup of 10 teams from the 16 participating in that study were surveyed about their attitudes towards protective headgear. The sample population consisted of 14-16 year old boys who had mostly played rugby since primary school and were the best players in their age group. The players attended schools in which rugby union is the main winter sport. While undertaking this study, the investigators observed trends within some school teams in which most players wore headgear, while at others only five to eight players wore headgear. It was unusual for no players in a school team to wear headgear; this observation includes schoolboy rugby teams outside of the research group.

Although this study is based on only a small sample of rugby teams, it provides valuable data about the patterns of, and reasons for, protective headgear use/non-use by these players. The attitudes of rugby players towards protective headgear has not previously been reported. It is possible that the wearing rates reported in this study are an overestimate of the true rate in general schoolboy rugby players because these figures are based on data collected at the end of a season during which a trial of headgear was conducted. Unfortunately, this study was not able to determine wearing rates before and after the trial. Furthermore, the player attitudes reported here may have changed over the course of the playing season, as they became more accustomed to wearing headgear. Future research should assess attitudes and safety behaviours at both the start and end of a trial of protective equipment.

The primary reason given for wearing headgear in this study was safety, even by players randomised to wearing headgear during a playing season. In contrast, the main reason for not 
wearing headgear was comfort. These two factors are also major determinants of teenagers' use of protective headgear in other sports such as cycling. ${ }^{18}$ Discomfort did not appear to be a concern to players who wore headgear, although they did report that their head was hotter than normal. Encouragingly, communication did not appear to be adversely affected by headgear. Role models of high level rugby players did not appear to have a strong influence on the type of headgear a player would choose. Non-users stated that parental pressure would be a major motivator for them to wear headgear; this has also been shown to be a factor in choosing to wear a cycling helmet in this age group. ${ }^{18}$

The players' responses suggest that they feel more confident and believe that they can tackle harder when wearing headgear than without it. This presumably reflects a belief that headgear is protective. If such players wear inappropriate or badly designed headgear, the combination of ineffective headgear and a belief that headgear is providing head protection, manifested in player confidence, may increase the risk of injury. Garraway et $a l^{17}$ argues that increased injury rates among rugby players are partially due to this phenomenon. If during their adolescent years players naturally adopt risky behaviours and modify their game tactics accordingly, then this could place them at an even greater risk of injury. ${ }^{2022} \mathrm{~A}$ before-after implementation study, with close surveillance of player behaviours and headgear use, is needed to formally determine if use of protective headgear increases injury risk because of more aggressive or confident play. Although some may argue that this is a reason for eliminating the use of protective headgear, the published injury data have shown that simply relying on technique and laws has not reduced the incidence of concussion. ${ }^{23}$ Therefore the need to reduce concussion remains unchanged.

One way of increasing knowledge about, and awareness of, injury risk and the benefit of protective headgear is to increase the use of headgear during training sessions, so that players regard headgear in the same way as other clothing necessary for the game. Given the potential role that parents have in encouraging young players to wear headgear, education programmes aimed at increasing the awareness of parents should also be promoted.

It is critical that headgear performance is improved to a level that meets the players' expectations. It is also important that players are educated to understand the nature and limits of the protection provided by headgear, so that dangerous play is avoided. Although adolescents may well understand and appreciate injury risk, this may not be a factor in their decision to wear or not wear protective headgear. For example, although teenagers believed that the risk of a severe cycling injury could be reduced by wearing a helmet, fewer than $45 \%$ of them actually used one regularly ${ }^{18}$; this was despite the fact that it was compulsory for all cyclists to wear one at the time of the survey.
As with the design of any protective equipment, there is a trade off in the design of headgear between safety and comfort. The safety performance of headgear is largely determined by the extent of head coverage, foam density, and thickness. The impact energy attenuation properties will be enhanced with denser and thicker foams. ${ }^{13}$ Unfortunately, this will also increase the mass of the headgear, which could increase injury risk. It is possible that players would find denser foam to be more uncomfortable too. An additional important design consideration is that the dimensions of the headgear should not interfere with normal play.

The safety performance of headgear can be improved beyond its current level in a way that enhances comfort and improves ventilation. This can be achieved by improving the padding over "at risk" sites on the head and reducing the padding at other areas. In a recent study, ${ }^{11}$ we showed that impacts to the temporoparietal region were more common and more likely to result in concussion. Impacts to the rear or top of the head are rare in the rugby codes. This injury prevention approach could be improved by encouraging players to wear shoulder pads (at present $40 \%$ of the sample wore shoulder pads) and harmonising the impact energy attenuation properties of headgear with shoulder pads. In this way, protection during shoulder-head impacts, a common cause of concussion, ${ }^{11}$ would be improved.

In summary, this study has shown that awareness of the safety benefits of wearing headgear and a previous injury are strong motivators for people to wear protective headgear. Education strategies focusing on the potential injury risk during rugby football and the benefits of wearing protective headgear should be developed for both players and their parents. The current attitudes and beliefs of junior football players should also be taken into account in the design of protective headgear and associated implementation strategies to ensure that headgear meets their expectations and does not lead to changed behaviours on the field.

The authors gratefully acknowledge the financial support of the New South Wales Sporting Injuries Committee and the Royal Australasian College of Surgeons and Warringal Hospital, Mc was funded by the National Health and Medical Research Council of Australia. No commercial sponsorship was obtained for this study and no conflict of interest exists. Rachel Breman, School of Health Sciences at Deakin University, is thanked for her assistance with the preparation of data for this paper.

1 Davidson RM. Schoolboy rugby injuries, 1969-1986. Med f Aust 1987;147:119-20.

2 Seward H, Orchard J, Hazard H, et al. Football injuries in Australia at the élite level. Med F Aust 1993;159:298-301. 3 Gerrard DF, Waller AE, Bird YN. The New Zealand Rugby Injury and Performance Project. II. Previous injury experience of a rugby-playing cohort. $\mathrm{Br} \quad \mathcal{F}$ Sports Med 1994;28:229-33.

4 Hughes DC, Fricker PA. A prospective survey of injuries to first grade rugby union players. Clin $\mathcal{f}$ Sports Med 1994;4:249-56

5 Garraway M, Macleaod D. Epidemiology of rugby football injuries. Lancet 1995;345:1485-7.

6 Bird YN, Waller AE, Marshall SW, et al. The New Zealand Rugby Injury and Performance Project. V. Epidemiology of

7 Jakoet I, Noakes T. A high rate of injury during the 1995 Rugby World Cup. S Afr Med f 1997;87:45-7.

8 Targett S. Injuries in professional rugby union. Clin $\mathcal{f}$ Sports Med 1998;8:280-5. 
9 Carson JD, Roberts MA, White AL. The epidemiology of women's rugby injuries. Clin f Sports Med 1999;9:75-8.

10 National Health and Medical Research Council. Head and neck injuries in football. In: Guidelines for prevention and management. Canberra: Australian Government Publishing Service, 1995.

11 McIntosh A, McCrory P, Comerford J. Head impact dynamics of concussion in rugby and Australian rules football. Med Sci Sport Exerc 2000;32:1980-4.

12 McIntosh A, McCrory P. Headgear effectiveness in under $15 \mathrm{~s}$ rugby union. $\mathrm{Br} \mathcal{F}$ Sports $\mathrm{Med}$ in press.

13 McIntosh A, McCrory P. Impact energy attenuation performance of football headgear. $\mathrm{Br} \mathcal{F}$ Sports Med 2000;34:337-41.

14 Wilson B. Protective headgear in rugby union. Sports Med 1998;25:333-7.

15 International Rugby Board (IRB). Laws of the game of rugby football. Dublin: International Rugby Board, 1996.

16 International Rugby Board (IRB). Law 4M-98g. Standard performance specification for specific items of players' performance specification for specific items of player
clothing. Dublin: International Rugby Board, 1996.
17 Garraway W, Lee A, Hutton S, et al. Impact of professionalism on injuries in rugby union. $\mathrm{Br} f$ Sports Med 2000;34:348-51

18 Finch C. Teenager's attitudes towards bicycle helmets three years after the introduction of mandatory wearing. Injury Prevention 1996;2:126-30.

19 Finch C, Vear P. What do adult squash players think about protective eyewear? Br $\mathcal{F}$ Sports Med 1998;32:155-61.

20 Patel DR, Luckstead EF. Sport participation, risk taking, and health risk behaviors. Adolesecent Medicine: State of the and health risk behaviors. A dol

21 Berger LR, Mohan D. Injury control. A global view. 1 st ed. Dehli: Oxford University Press, 1996.

22 Tursz A. Adolescents' risk-taking behavior, myth or reality: evidence from international data. In: Mohan D, Tiwari G, eds. Injury prevention and control. London: Taylor \& Francis, 2000:149-66.

23 McCrory P. Neurological injuries in rugby and Australian rules football. In: Jordan B, Tsaris P, Warren R, eds. Sports neurology. Philadelphia: Lippincott-Raven, 1998:441-9.

\section{British Association of Sport and Exercise Medicine in association with the National Sports Medicine Institute}

\section{Education programme 2001}

General sports medicine

Lilleshall Hall National Sports Centre, Shropshire

\section{Current concepts}

Topic, date, cost, and location to be confirmed

Injury management and medicine: thorax, groin, pelvis and hip

Lilleshall Hall National Sports Centre

General sports medicine

Lilleshall Hall National Sports Centre

Practical sport and medicine meeting

Club La Santa, Lanzarote

Families and non-delegates welcome; booking deadline 31 July

Diploma preparation course

Exact date and location to be confirmed

\section{BASEM Congress}

Date, cost, and location to be confirmed

Injury Management and Medicine: lower limb

Lilleshall Hall National Sports Centre

\section{Current Concepts}

Topic, date, and location to be confirmed
October

22-27 April

1 May

8-13 July

23-28 September

4-11 October

Oct/Nov

18-23 November

\section{December}

For further details of these courses please contact Mr Barry Hill, The National Sports Medicine Institute, c/o Medical College of St Bartholomew's Hospital, Charterhouse Square, London EC1M 6BQ.

Tel: 02072510583 (ext 237); fax: 0207251 0774; email: barry.hill@nsmi.org.uk Web site: www.nsmi.org.uk 